Marcelo Henrique Leite

Mauro Wilton de Sousa

Rafael Pompéia Gioielli

\title{
Práticas de recepção mediática: cultura da imagem e identidade cultural*
}

\section{Resumo}

A cultura da imagem caracteriza hegemonicamente o processo mediático na contemporaneidade e exerce papel importante na configuração das praticas sociais de vida. $\mathrm{O}$ presente texto indaga sobre as mediações, especialmente a identidade cultural, nesse contexto.

\section{Introdução}

O presente trabalho é marcado por um esforço interdisciplinar. É resultado da contribuição das pesquisas de três autores, a partir de três textos distintos e com redações diferenciadas, mas que procuram conjuntamente estabelecer olhares complementares sobre uma mesma problemática: as mediações presentes nas práticas de recepção mediática em um mundo marcado, de um lado, por uma cultura comunicacional baseada cada vez mais na imagem, e, de outro, pela diversidade e pluralidade culturais que se acentuam hoje na sociedade globalizada. Com a preocupação de problematizar estas questões mais do que indicar conclusões, aqui se busca dimensionar os nexos existentes entre esses dois "mundos", na perspectiva das práticas de recepção mediática, envolvendo as temáticas da cultura da imagem, da identidade cultural e do espaço publico mediático. Cada um dos autores focou e abordou as perspectivas teóricas presentes em uma dessas temáticas, valendo-se da sistematização de revisões bibliográficas em suas áreas de estudo. A idéia é traçar um olhar interdisciplinar sobre as práticas de recepção mediática em meio ao mundo globalizado.

\section{Imagem fotográfica e tempora- lidade social ${ }^{1}$}

Os acontecimentos terroristas ocorridos com um trem na Espanha, em março de 2004, foram o estopim de uma série de manifestações em todo o mundo sobre o terrorismo internacional. Mas alguns detalhes do atentado ficaram circunscritos ao domínio dos editores e profissionais dos maiores jornais do mundo. A maior parte da imprensa internacional usou uma imagem, fornecida pela agência Reuters, dos destroços do trem espanhol. Porém, um detalhe que chamava a atenção nessa fotografia era uma pequena parte que se caracterizou como restos de um membro inferior do corpo humano encontrado a alguns metros de distância. Por todo o mundo, essa mesma fotografia teve. uma rápida e sutil manipulação a fim de se encobrir, ou até mesmo excluir, o fragmento. Os jornais The Times, Gazet Van Antwerpen e The Telegraph preferiram excluir o referido detalhe. $\mathrm{O}$ jornal The Guardian optou por mudar a cor da parte do corpo para cinza, a fim de ser menos perceptível. Já os jornais The Washington Post, Daily News, El Pais e Folha de São Paulo optaram por deixar a imagem intacta.
Marcelo Henrique Leite, Mestrando em Ciências da Comunicação pela ECA-USP, Especialista junto ao Laboratório de Mídias Audiovisuais do CTR-ECA-USP.

Mauro Wilton de Sousa, é Professor e Pesquisador junto ao Departamento de Cinema, Rádio e Televisão da ECAUSP.

Rafael Pompéia Gioielli, Mestrando em Ciências da Comunicação pela ECA-USP, docente no curso de Comunicação Social da UniSant'anna em São Paulo.

* Texto apresentado no GT-Mídia
e Recepção, ALAIC, La Plata,
Argentina, 2004.

(01) Vide a respeito Leite, 2004. 
Esta imagem fotográfica suscitou discussões nos principais jornais do mundo sobre a ética nos meios de comunicação em tempos em que a tecnologia digital possibilita aos editores de imagem alterar substancialmente e muito rapidamente o sentido e valor das fotografias. Decorrem daí indagações sobre $\mathrm{o}$ fato, com $\mathrm{o}$ objetivo de analisar quais foram os significados trazidos pela omissão, ou não, do detalhe, bem como interpretar o lugar da imagem no contexto político-cultural: o tempo social padronizado de distribuição globalizada de conteúdos mediáticos corresponde ao tempo social de sua recepção-consumo? A alteração do detalhe da fotografia rompe culturalmente com a sua distribuição globalizada, já que sua maior parte (80\%), manteve-se inalterada? No contexto de discussão sobre as múltiplas possibilidades da imagem, da mídia, do tempo e da cultura na atualidade, aqui se situa a proposta de especular sobre o papel da imagem, em específico da fotografia digital, como espaço de construção de realidades e verdades na contemporaneidade.

Dois teóricos são aqui referenciados na busca de entendimento do papel da imagem como construtora de realidades no contexto de um mundo globalizado: Vilém Flusser especula sobre uma futura filosofia da fotografia em tempos onde a imagem técnica $^{2}$ torna-se onipresente e Jean Baudrillard indaga sobre a filosofia da imagem-simulação como construtora de um nova realidade.

Para Flusser, "as imagens são superfícies que pretendem algo. Devem sua origem à capacidade de abstração específica que podemos chamar de imaginação." (2002:7). Nessa mesma linha, ele fala sobre a imaginação: "imaginação é a capacidade de codificar fenômenos de quatro dimensões em símbolos planos e decodificar as mensagens assim codificadas. Imaginação é a capacidade de fazer e decifrar imagens" (2002:7). A imagem, portanto, seria nossa capacidade de imaginar, criar e decodificar o mundo que nos cerca, daí sua importância na caracterização da atualidade, efetivando-se como construtora do conhecer, do saber, do prazer, da vida.

Entretanto, ao representar o mundo em seus mais diversos olhares, as imagens exercem o papel de mediadoras entre nós e esse mundo, como se fossem mapas de um território, e essa mediação faz desse mapa um espaço mais importante do que o próprio território: "imagens têm o propósito de representar o mundo. Mas ao fazê-lo, interpõem-se entre o mundo e o homem. Seu propósito é serem mapas do mundo, mas passaram a ser biombos" (2002:9).

É o que Flusser resume quando assinala: "ou seja, as imagens técnicas (e, em primeiro lugar, a fotografia) deviam construir denominador comum entre o conhecimento científico (...) $\mathrm{Na}$ realidade, porém, a revolução das imagens técnicas tomou rumos diferentes: ela não toma visível o conhecimento científico, mas o falseia; não reintroduz as imagens tradicionais, mas as substitui; não torna visível a magia subliminar, mas a substitui por outra." (2002: 18).

Sendo assim, nossa capacidade de imaginação torna-se alucinação, estamos entre biombos, e o homem fica incapaz de poder decifrá-las, isto é, de decompor as inúmeras dimensões perdidas no ato de registrar a imagem fotográfica.

Essa abordagem sobre o papel da imagem técnica na atualidade e suas conseqüências frente à cultura são as intersecções que ligam os postulados iniciais de Flusser com as indagações de Baudrillard. Para esse, a abstração já não é a do mapa, do duplo, do espelho ou o do conceito: "A simulação já não é a simulação de um território, de um ser referencial de uma substância. $\mathrm{O}$ território já não precede o mapa, nem lhe sobrevive. É agora o mapa que precede o território precessão dos simulacros" (1981:8). Caracteriza-se aqui, tanto em Flusser quanto em Baudrillard, a dimensão de 
superioridade da simulação do mapa frente ao território.

A perspectiva filosófica de Flusser busca, inicialmente, denunciar a possibilidade do fotógrafo tornar-se um funcionário do equipamento. Para ele, o futuro da fotografia está na capacidade humana de ainda poder construir os mapas dos territórios e também intervir de forma presente nos processos de elaboração da imagem. Já a filosofia de Baudrillard aponta a perda de referencial trazido pelas imagens simuladas no contexto da sociedade atual. Ele assim se refere a essa ruptura com a realidade através da simulação: "A partir do momento em que vivemos no tempo real, em que os acontecimentos desfilam como num 'traveling' o tempo de reflexão sofre um curto circuito. A tela quebrou a distância entre o acontecimento, o fato e a percepção". 3

Tanto Baudrillard quanto Flusser apontam, mesmo que de forma indireta, o papel do tempo e da cultura na construção da imagem na sociedade atual. Para o segundo, estamos perdendo nossa capacidade, através da imagem técnica, de recodificar o tempo e o espaço abstraídos pelo processo de criação das imagens. Tal crise decorre da caracterização do tempo como fator primordial na capacidade cognitiva de absorção e interpretação das informações visuais.

As indagações sobre a atualidade das sociedades contemporâneas, trazidas pelos dois pensadores, são espaços teóricos que possibilitam o entendimento da globalização da imagem como forma de massificação e simulação, situações essas, alcançadas em meio a economia global. Daí a constatação empírica: quase a totalidade dos grandes jornais mundiais usou, a mesma matriz fotográfica do atentado, o que reflete esse caráter globalizado e ao mesmo tempo padronizado com que a mídia trata as informações hoje.

Porém, conforme abordado nas questões aqui colocadas, qual o poder que $\mathrm{o}$ detalhe fotográfico trouxe à imagem e a sua conseqüente utilização ou não, no contexto acima exposto? Haveríamos de pensar que, apesar de ter a maior parte da fotografia $(80 \%)$ globalizada, isto é, não alterada desde sua produção, houve na mesma foto um outro contexto, o dos $20 \%$ do detalhe e que não só suscitaram as discussões sobre seu conteúdo, como também a presente reflexão.

As considerações teóricas apontadas por Flusser e Baudrillard parecem, no entanto, enfraquecidas quando se procura compreender a sutileza do detalhe rompendo com uma cadeia de aspectos massificados das mídias e da cultura na atualidade. Diante disso, há de se considerar a existência de outros fatores que estão envolvidos e que não se restringem só ao caráter de massificação da informação através da reprodução técnica da fotografia. Nesse sentido, outras posturas teóricas que abrangem de uma forma mais completa e complexa a imagem, a mídia e a cultura apresentam possíveis caminhos para se entender a importância da manipulação do detalhe e dos questionamentos derivados, como para romper com o modelo fechado do simulacro baudrillardiano.

Abordagens mais abrangentes sobre a relação entre comunicação e cultura possibilitam um novo olhar. Assim, observe-se que para MartínBarbero não se trata mais de medir os efeitos produzidos pelos meios de comunicação e suas imagens sobre as pessoas, mas construir uma análise mais integral do consumo pelos diversos segmentos, entendendo-os como "conjunto de processos de apropriação de produtos" (1997:290). Isso esclarece sobre os novos modos de consumo: "não estamos nem no terreno da tão combatida 'compulsão consumista' nem no repertório de atitudes e gostos recolhidos e classificados pelas pesquisas de mercado, mas tampouco no vago mundo da simulação e do simulacro baudrillardiano" (1997: 290).

Ao se avaliar a importância do detalhe fotográfico sob esta ótica, percebe-se que o contexto de leitura da
(03) Jomal Folha deS. Paulo, Cademo Mais, Ooutrolado da matéria-prima da dor (trad. "Le Monde"), p. 3, 02 novembro de 2003. 
fotografia por diversos jornais em diferentes países, fez-se perpassando sentidos culturais que de alguma forma pressupõe os leitores e suas práticas de vida, ainda que estejam presentes interesses mercadológicos e uma matriz global. Esses sentidos levaram a que cada prática cultural, no ato de se apropriar do material fotográfico, o redefinisse segundo essas mesmas práticas. A omissão ou não do detalhe deu-se nesse processo.

Diferentes mediações culturais se colocam de forma hegemônica nessa leitura decodificada, como em um espaço de confronto, de relações de forças dentro de um sistema onde grupos passam a ser preponderantes, mas não exclusivos. Mediações como a da cotidianidade familiar, da temporalidade social e da competência cultural, como apontado por MartínBarbero, entram nesse processo de construção de hegemonias. No caso aqui estudado, vale a pena ressaltar um pouco mais sobre a pertinência das mediações ligadas à temporalidade social e à competência cultural na caracterização das diversas utilizações dadas à fotografia em questão.

O tempo social tem uma contextualidade histórica. $\mathrm{Na}$ atualidade da sociedade capitalista e industrial, o tempo é sempre um componente vital e muito valorizado pelo capital, que o mensura, planifica e calcula na produção. Este é o contexto do tempo cronológico, ou o tempo do relógio. Porém, essa forma de se pensar o tempo começa a conviver com uma visão mais diversificada, isto é, de uma cotidianidade que começa e acaba para recomeçar novamente, ou um tempo não feito de unidades contábeis, ou cíclicas, mas de fragmentos de tempos assim como o tempo do mundo pessoal e cultural vividos. Bergson, Heidegger, entre outros, introduzem o conceito de temporalidade nas questões relativas ao tempo nas sociedades capitalistas modernas. Essa apropriação do caráter de temporalidade também está presente nos estudos de Martín-Barbero, sinalizando a importância da recepção mediática e de seu contexto históricocultural na forma diversificada de apropriação tanto da imagem quanto dos modos e gêneros com que ela se realiza na indústria cultural contemporânea.

Assim, o tempo torna-se um valor de extrema significação na trama de diversidade cultural, dado que o tempo social da produção da imagem tem dimensão de poder que não se esgota na sua própria produção, manipulação e estandardização pelos medias, mas tem sua fonte de poder igualmente ampla e até muitas vezes superior na diversidade dos significados da temporalidade social dos receptores. É neste contexto, que a massificação, o agenciamento, o consumo e a simulação propostos por Flusser e Baudrillard estariam, em princípio, a contento desse primeiro momento, o da produção da imagem, mas insuficientes para darem conta da pluralidade de acepções existentes quanto ao sentido presente no detalhe fotográfico. Em síntese, o detalhe fotográfico teve sua significação definida pela dimensão cultural que lhe foi atribuída por cada jornal em cada país. $\mathrm{O}$ detalhe determinou o sentido hegemônico da foto.

\section{Mediação e identidade cultural: do nacional ao global ${ }^{4}$}

Se durante toda a modernidade as identidades estiveram protegidas no interior das diversas culturas nacionais, com a consolidação recente do mundo global e o conseqüente enfraquecimento dos Estados e de suas fronteiras, estão sendo levadas a se movimentar em busca de novas configurações. Isso se deve ao fato de que os discursos que forneciam os mapas simbólicos dentro dos quais se constituíam, agora se encontram tensionados pelos fluxos globais de informação, mercadorias e pessoas. A globalização não só colocou em xeque a capacidade do Estado Nação em circunscrever e limitar os processos culturais ao seu interior, como ampliou largamente as trocas simbólicas e as redes de construção 
de significado dentro das quais as identidades se sustentam. Assim, aquela que era a configuração hegemônica da identidade cultural durante toda a modernidade, a nacional, entrou em uma forte crise de significação, o que tem transformado decisivamente as percepções dessa questão. Sabe-se que no interior de cada nação, ou perpassando por várias delas, há outras redes de significado sustentando outras posições-desujeito que se apresentam mais relevantes na construção do pertencimento. Hoje, a nacionalidade já não é suficiente para posicionar e diferenciar os sujeitos nas relações estabelecidas na dinâmica de suas vidas cotidianas.

Mas será que podemos falar que a crise da identidade nacional é uma crise generalizada da identidade? Ao que indicam as práticas cotidianas, essa afirmação não seria verdadeira. Afinal, o que se observa é que a identidade ao romper com sua faceta nacional, vive um momento rico de experimentações, hibridizações e fragmentações, o qual vem pluralizando suas configurações. Quando sai de campo a mediação da nação, entra em jogo uma variedade de outras: a tradição, a religião, a raça, a sexualidade, o lazer, as práticas de consumo, entre uma infinidade. Diversificadas, as identidades culturais tornaram-se duplamente incertas. A dúvida não está apenas nos posicionamentos hegemônicos que assumem no cotidiano. $\mathrm{O}$ processo contínuo de reconstrução na qual estão inseridas gera também uma crise de conceitos e obriga a uma revisão do entendimento fixado para o assunto desde a modernidade.

Ainda que haja alguma controvérsia a este respeito, acreditamos estar diante de um momento histórico de transformações sociais significativas. De fato, o capitalismo nascido na modernidade ainda se mantém como o modelo econômico hegemônico, mas sua evolução em direção à globalização associada ao mal-estar que se abateu sobre a modernidade nas décadas recentes e também às possibilidades de interação abertas pelas novas tecnologias informacionais criou um cenário novo que evidencia mudanças sociais substanciais. Algo que interfere diretamente nos processos de construção das comunidades, no pertencimento e nos obriga a repensar a identidade cultural.

Apesar de se encontrar em uma nova fase, o interesse pelo tema da identidade cultural nas ciências sociais não é um fenômeno recente e diversos entendimentos vem sendo formulados ao longo do tempo. Sinteticamente, e de maneira recorrente em quase toda a pluralidade de visões disponíveis, a identidade é entendida como aquilo que posiciona e localiza o indivíduo frente ao diverso. É a mediação que possibilita estabelecer relações de igualdade e singularidade, de inclusão e exclusão em meio à coletividade. Um recurso que opera baseado em sistemas de classificação e atua no sentido de identificar e diferenciar o sujeito dos demais indivíduos e dele próprio ao longo do tempo. Está vinculada a uma idéia que é simbólica e a uma prática concreta pelo meio da qual ganha vida (SILVA, 2003).

"A identidade é um significado cultural e socialmente atribuído" (SILVA 2003:89). Precisa ser entendida como um processo simbólico, uma teia de significados que se constrói no interior das relações sociais. Trata-se do resultado obtido na eleição e articulação de elementos diversos diante das diferentes situações de vida experimentadas pelos sujeitos, um sentido negociado no interior do universo cultural do indivíduo e do(s) grupo(s) que o cerca. Assim, é contingente, passível de mudanças e posições múltiplas. A identidade não se dá a priori da vida social, mas através desta. Em cada contexto social experimentado pelo sujeito em que há novas relações, há uma nova articulação e novas posiçõesde-sujeito. Portanto, uma configuração diferenciada da identidade. Hall (2003:109) explica que: "é precisamente porque as identidades são 
construídas dentro e não fora do discurso que nós precisamos compreendê-las como produzidas em locais históricos e institucionais específicos, no interior de formações e práticas discursivas específicas, por estratégias e iniciativas específicas."

É apenas quando inserida em um contexto específico que a identidade ganha contornos e significado. Por isso, em cada situação, para cada grupo de sujeitos, há mediações específicas atuando. Numa dada relação, a mediação hegemônica pode ser a diferença de gênero e as identidades serão construídas a partir da idéia de "homem" e "mulher". Em outra situação, a mediação fundamental pode ser a cor da pele e os mesmos sujeitos serão reidentificados, agora como "brancos" ou "negros". As identidades estão sempre em construção, dependentes desses sistemas classificatórios estabelecidos no momento especifico em que as diferenças são evocadas. Por traz da construção das identidades há sempre a mediação de um processo simbólico e discursivo que marca as diferenças.

Se nas sociedades pré-modernas a comunhão das práticas tradicionais e da religiosidade eram os fundamentos que conferiam a identidade aos indivíduos, com o processo de secularização envolvido na modernidade e o conseqüente distanciamento e negação desse vínculo com o passado, a identidade aparece pela primeira vez como uma questão a ser pensada, afirmada. Antes, eram os ritos, os mitos, a história partilhados os pontos de sustentação que mantinham vivas e reunidas as diversas tribos, clãs e lhes conferiam identidade. Com a negação da tradição promovida pela filosofia moderna, bem como com a consolidação de Estados multiétnicos, é a cultura nacional que surge como o novo elemento de mediação capaz de constituir as novas identidades. Tratase de um elemento imaginado, simbólico e discursivo que passa a garantir a identidade às comunidades recém criadas. Nesse sentido, as culturas nacionais podem ser descritas como tradições inventadas, idealizadas, que sustentam uma comunidade que só pode ser concebida como sendo imaginada (HALL, 2003A). Isso, porque quando da delimitação das fronteiras nacionais, a população que se inscreve no âmbito do Estado nacional não é necessariamente uma formação culturalmente homogênea ou ligada por elos de solidariedade e por um passado comum. A cultura nacional é justamente a rede de significados forjada com o objetivo de garantir a unidade representacional ao conjunto de pessoas reunidas na nação. Essa é uma comunidade simbólica que se sustenta imaginariamente por meio da representação. Assim Hall (2003A: 50) afirma que "uma cultura nacional é um discurso - um modo de construir sentidos que influencia e organiza tanto nossas ações quanto a concepção que temos de nós mesmos".

Porém, na contemporaneidade, quando o capitalismo global passa a integrar o mundo em um único mercado e não se irradia mais a partir de um centro, mas opera de maneira dispersa e integrada por todo o globo, as trocas simbólicas mundializadas e o enfraquecimento dos diversos Estados enfraquecem o poder de significação das identidades nacionais. Aquele discurso que oferecia um mapa para a constituição das identidades na geografia moderna perde sua capacidade de orientá-las quando se estabelece o novo mundo global. O que nos interessa perceber aqui é que o processo de globalização ao se sobrepor à configuração geopolítica da modernidade, diminui gradativamente o lugar do Estado Nação como instituição mediadora das identidades. A globalização precisa ser concebida como um paradigma que opera pela desnacionalização e desloca as economias, as culturas, as políticas e as comunidades em direção a uma economia-cultura-política-

comunidade-mercado-mundo. Porém, esse evento que induz ao enfraquecimento do nacional, ao passo que ruma em direção a um processo de mundialização, também abre espaço 
para o resgate de algumas tradições que haviam sido encobertas pelo processo de consolidação do Estado Nação. Se as diversas culturas nacionais que se constituíram como a negação da tradição, ao serem fragmentas e rompidas rumam em direção a uma configuração que é mundializada, a cultura que Ortiz (2003) denomina de internacional popular mas também a outra que retoma a tradição. Os fundamentalismos religiosos tão observados nos dias de hoje são exemplos desse resgate. Assim, o processo que envolve a construção da cultura na sociedade global não se dá de maneira homogênea ou em sentido único como foi na modernidade. Ao contrário promove também a diversidade. A tradição e as trocas que constituem novas comunidades aparecem como contraponto a uma possível homogeneização.

Obviamente, a relação entre a recuperação da tradição e a inserção na cultura internacional popular não é uma movimentação horizontal e equilibrada. Há, na verdade, um processo de reconstrução cultural em que esses dois sentidos se somam, se hibridizam, se misturam, sendo que o sentido hegemônico só se revela no contexto concreto do acontecimento. $\mathrm{O}$ que opera nesse momento de reconstrução da cultura é o processo que Hall (2003A) denomina de tradução. A partir dele, cada grupo de indivíduos pode ressignificar ou se apropriar da cultura mundializada tendo como base a cultura tradicional ou, ao contrário, fazer a tradução da tradição sustentando-se na cultura mundializada. O resultado é um espectro cultural diverso, mas em permanente comunicação.

No mundo globalizado há um fluxo permanente de pessoas, informações, bens materiais e simbólicos. Esse fluxo opera por meio do comércio, das migrações, da indústria cultural e das redes informatizadas de troca de informações e acaba pluralizando as práticas culturais e gerando novos ambientes de pertencimento. Parece interessante a idéia de que é na partilha desses universos culturais plurais, vistos aqui como espaços de representação, que estão surgindo as novas comunidades e sendo sedimentadas as identidades contemporâneas. $\mathrm{Na}$ mídia, nas redes de computadores, na publicidade, na moda circulam e são formados ambientes culturais que sustentam práticas de vida, comportamentos, pensamentos e gostos. É através do acesso aos bens materiais e simbólicos e no seu consumo por públicos específicos que essas parecem ganhar forma como as novas comunidades do mundo global. Como propõe Canclini (1999) essas comunidades estão se formando como redes de consumidores que compartilham universos culturais próximos e os mesmos padrões de consumo. Comunidades desterritorializadas que podem constituir-se dessa maneira graças ao fluxo mundializado de bens materiais e simbólicos. É' na apropriação de produtos, sejam culturais ou não, que as identidades são manifestadas e construídas. $\mathrm{O}$ ato do consumo é o lugar de materialização das identidades no mundo globalizado.

Se na modernidade as identidades vinculavam-se a comunidade imaginada da nação, no mundo globalizado vinculam-se a redes de consumidores mediadas pelos media. Se ontem materializavam-se através de símbolos como a bandeira e narrativas como a história e o mito fundacional nacionais, hoje encontram sua materialidade nos produtos da moda e da comunicação global e na carga simbólica que esses carregam. Se na modernidade era o Estado, através de instituições como a Escola e os museus, o responsável por manter viva a representação da identidade, na globalização essa função é desempenhada pelos meios de comunicação e pela publicidade que mantêm clara a simbologia dos produtos e permitem que os consumidores se diferenciem a partir de sua apropriação. Porém, se a cultura
(12) Nietzsche, Friedrich; Além do beme do mal-Prelúdio para uma filosofia do futuro. São Paulo: Ca. das Letras, 1992. Pg. 66. (13) Ranoya, Guilherme; $O$ individuo perante a organização: os lacos da propriedade intelectual. Monografia Festcorp. São Paulo, ECA-USP, 2003. Pg. 53. 
da modernidade negava a tradição, no plano da globalização essa não é descartada, integra-se pela tradução à rede de construção de significados como mais um objeto de significação e de consumo.

$\mathrm{Na}$ dinâmica do mundo global, o discurso da identidade imaginada na nação como projeto de progresso perde poder de significação e representação e é fragmentado em outros discursos como o da negritude, do esporte e da sexualidade sustentados nas práticas cotidianas de consumo. A adesão dispersa a esses discursos acaba por criar uma comunidade distanciada fisicamente, mas que se aproxima através da partilha de um mesmo imaginário, comportamento e rede de significação. Levar para a esfera do consumo a representação das identidades no mundo global não é a fetichização dessa, mas a possibilidade de manifestá-la em um mundo em que a circulação de idéias e produtos é vertiginosa e os universos culturais e as comunidades imaginadas se transformam com extrema rapidez. É o mundo do consumo que oferece respostas rápidas a uma possível flutuação das identidades e, devido ao seu alcance ampliado, possibilita a construção da identidade e da diferença na partilha de uma ou mais comunidades (sempre imaginadas), ainda que em distância, ainda que desterritorializadas.

\section{Identidade cultural e espaço publico $^{5}$}

$\mathrm{O}$ estudo sobre as praticas de recepção mediática se apoiam cada vez mais em perspectivas interdisciplinares. É o reconhecimento da complexidade de seu objeto tanto quanto da pluralidade de enfoques que hoje se colocam possíveis de serem aglutinados e disponibilizados para sua compreensão. Assim, se de um lado é desafiadora a compreensão da identidade cultural numa sociedade com as marcas da sociedade contemporânea, é igualmente complexo entender $o$ papel do processo comunicacional, sustentado hegemonicamente em suportes imagéticos, na construção dessas praticas sociais. Nesse sentido, é instigante a perspectiva de Beaud (1985:151) quando afirma ser importante buscar "a ligação entre as práticas sociais e a evolução conjunta do espaço público e dos processos de comunicação".

O sentimento de pertencimento é uma das dimensões presentes nas praticas de recepção mediática. Pode parecer uma temática de importância secundária, quando os eixos de investigação se situam mais nos âmbitos do poder desses mesmos meios sobre as pessoas, da qualidade cultural de sua produção ou da construção da cidadania no contexto da sociedade globalizada. Essa é, por outro lado, uma temática que de imediato parece mais se associar a estudo de questões da intimidade pessoal, de vida comunitária de pequenos grupos, pouco indicando sobre o público político e social, sobre os meios de comunicação cada vez mais consumidos.

De fato, o estudo do sentimento de pertencimento tem sua origem vinculada aos estudos sobre socialização e especialmente aos que se reportam à organização e funcionamento de comunidades baseadas em contato face a face. É nessa perspectiva que surgem as acepções de sentimento de pertencimento, fazer parte, inserção, ser membro, participar (Silverstone, 1999). Horckheimer e Adorno (1973:156) citam Warner para definir comunidade como sendo "uma pluralidade de homens com interesses, comportamentos e finalidades comuns, em virtude de sua pertença ao mesmo grupo social como estrutura constante em toda e qualquer forma de sociedade antiga ou moderna". Essas acepções originais de comunidade foram sendo ampliadas na extensão de sua significação e hoje se percebe a pluralidade com que os conceitos de comunidade e de pertencimento são utilizados: Comunidade Imaginada, Comunidade Virtual, Comunidade de 
Apropriação, Comunidade Interpretativa, Comunidade Hermenêutica, Comunidade e Comunicação Comunitárias, entre outros.

Veja-se, por exemplo, que pertencimento também se liga à socialização política, como observa Monteiro: “a reivindicação (e o reconhecimento) de direitos supõe, em princípio, que os atores sociais se sintam parte de uma sociedade política mais abrangente do que aquela definida pelo seu pertencimento à rede de sociabilidades primárias (família, etnia, religião, etc.). No entanto, talvez esteja aí um dos nós górdios da questão da democracia do mundo contemporâneo: o enfraquecimento da capacidade dos sistemas democráticos de gerar sentimentos de pertencimento a coletividades mais abstratas organizadas em torno de reconhecimento de direitos" (1996:104).

Essas diferentes conceituações de pertencimento são indicativas da pluralidade de significações que envolve. Duas perspectivas são adiante apontadas.

\section{Pertencimento, identidade e espaço público \\ Entre diferentes pesquisadores} que recentemente têm envolvido a temática do pertencimento aos estudos sobre o processo comunicacional estão Canclini e Martín-Barbero. O segundo trabalha a questão em vários de seus textos, nos quais assume duas direções complementares: primeiro quando reconhece que a sociedade contemporânea é fragmentada, contexto que facilita a determinação e transformação de questões como aquelas relativas a povo e nação. Povo vem sendo substituído por público, base de um novo espaço público à medida que há um entrelaçamento do público com os novos modos de simbolização e representação abertos pelas redes comunicacionais e pelos fluxos de informação (1997:91). Por outro lado, ao reconhecer a desespacialização das cidades, o autor indica que vêm surgindo "reconfigurações do sentido de pertencimento e identidades cidadãs, num contexto conflitivo entre povo-público, de uma cidade cada vez mais mediada por veículos de comunicação e de informação donde a cidade virtual" (1997:92). Esse lugar mediador dos diferentes media e especialmente aquele que ocupa na busca de identidade numa sociedade fragmentada se revela quando se percebe que "se a televisão atrai é porque a rua expulsa, é dos medos que vivem os meios" (1996:33). Medos que provêm secretamente da perda do sentimento de pertencimento em cidades nas quais a racionalidade formal e comercial acaba com a paisagem em que se apoiava a memória coletiva (1996:33).

Numa segunda direção, o sentimento de pertencimento é visto, em textos de Martín-Barbero, associado ao consumo, ora sendo "espaço de integração e comunicação de sentidos, como modo de circulação e popularização de sentido", ora sendo espaço de objetivação de desejos: “dimensão fundamental (...) a dimensão libidinal, dimensão desejante(...) consumir faz parte da relação desejante entre sujeitos da interpretação que nos constitui como sujeitos" (1995:62). Os meios de comunicação se situam como mediadores desse caos e dessa fragmentação, ou muitas vezes chegam a ser "uma compensação dessa desarticulação, produzindo no imaginário das pessoas certas articulações (...) compensando as novas formas de solidão, os novos isolamentos, através da diferenciação, as convocações tribais que estimulam a configuração de audiência e de públicos" (1995:152).

Os diferentes media são vistos enquanto espaço aglutinador na fragmentação social, espaço de centralização nos processos de exclusão das pessoas. Identidade se confunde com a busca de um comum, com mediações entre o vivido isolado, fragmentado e diferente, e a necessidade de seu oposto pela inclusão. Embora essa noção de identidade exija ser melhor detalhada, essa dimensão 
política, através da qual se introduz o conceito de cidadania, é chave nos estudos Canclini, sobretudo pela análise do significado do consumo na vida contemporânea.

É o que se observa quando o autor diz: "ser cidadão não tem a ver com os direitos reconhecidos pelos aparelhos estatais para os que nasceram em um território, mas também com as práticas sociais e culturais que dão sentido ao pertencimento e fazem com que se sintam diferentes os que possuem uma mesma língua, formas semelhantes de organização e satisfação de suas necessidades" (1995:22).

Assume-se que a cidadania não se refere apenas à satisfação dos direitos que levam à igualdade mas também daqueles que se reportam à diferença como componentes da democracia. A questão envolve o debate sobre as ciladas que a diferença pode assumir quando tomada como discriminação, o que leva à sua denúncia, e seu lugar transformador ou então como justificativa conservadora de se buscar a sua manutenção pelo direito de igualdade (Pierucci, 1999).

O pertencimento se reforça como estratégia simbólica de busca de inclusão frente contextos de fragmentação derivados de processos de desigualdade cada vez mais intensos. Os meios de comunicação, especialmente os que se apóiam na imagem, como mediadores desse processo e atuando na esfera simbólica através de gêneros e formatos tanto quanto de veículos diversos, lidam com um comum social de informações, valores e necessidades que constituem a representação do que passa a ser buscado e circulado na concretude de práticas cotidianas, segundo espaço e tempo sociais definidos.

Saliente-se, no entanto, a significação da busca de pertencimento a um comum social quando se concebe este se expressando através do que se denomina de espaço público. A busca de pertencimento teria a sua realização quando a identidade se realiza na esfera pública. É bem verdade que o conceito de esfera publica é complexo, sobretudo a partir das perspectivas de Habermas, na qual predomina a importância de que esse espaço seja antes de tudo um espaço de argumentação, discursiva, de senhores livres, com fins politicosociais.

Pode-se aqui, no entanto, a partir de Miege (1995) sinalizar o espaço publico mediático como sendo basicamente um espaço de expressão dos diferentes tipos e razões de conflitos que permeiam a vida social. Faz evidenciar o campo de formação simbólica que constrói a opinião publica, a vontade democrática, e como tal exprime os conflitos de uma sociedade entre a igualdade desejada e a desigualdade vivida.

As perspectivas aqui apontadas quanto ao sentimento de pertencimento, embora derivadas de tradições distintas de pesquisa e voltadas a objetos igualmente diferentes de estudos, têm muitos aspectos em comum: 1. A compreensão da dimensão simbólica que estrutura o sentimento de pertencimento; 2. O reconhecimento do lugar singular que a comunicação representa hoje na construção de identidades culturais tanto quanto na construção e espaços públicos nos quais se efetivam dimensões novas que permeiam a compreensão do sentimento de pertencimento e as práticas de recepção mediatica; 3 . O sentimento de pertencimento parte da esfera subjetiva para se realizar na dimensão de algo que ora é chamado de comum, ora de público, mas que alguma forma traduz e evidencia a relação entre as práticas vividas no cotidiano e sua realização no social e cultural mais amplo, no estar junto coletivo. É essa dimensão de comum social que os diferencia e aproxima.

\section{Pistas para pensar a comunicação na globalização}

As perspectivas de análise indicadas ao longo do presente artigo, ao mesmo tempo que colocam em evidência a estrutura globalizada que se manifesta na circulação e produção de informações e imagens na comunicação contemporânea, também atestam a complexidade que marca a 
recepção dessas mesmas imagens e informações, esta sempre envolta na perspectiva das mediações que caracterizam as práticas sociais em um tempo e espaço definidos. As diversas comunidades que se efetivam através ou apesar das redes globais de comunicação e as formas com que negociam e dotam de sentido os signos globais, como a imagem do atentado ao trem espanhol, nos forçam a pensar que a significação do processo comunicacional vai além das estratégias econômicas que sustentam sua produção.

Se retomarmos as idéias de mundialização da cultura e de tradução cultural para analisar a distribuição global da imagem fotográfica do atentado e, principalmente, a manipulação que marcou e dotou de sentido a sua reinserção no tempo e espaço definidos de sua recepção, temos indícios para pensar que a circulação globalizada de informações e imagens só se toma um processo efetivo de comunicação na perspectiva de sua inserção local através das práticas de recepção. É na dimensão das mediações que marcam os contextos de recepção que a imagem se efetiva como portadora de sentidos e que se pode falar em disputas quanto ao seu significado social. Em meio à pluralização do espaço público mediático, pensar a comunicação na globalização pressupõe especial atenção às novas dinâmicas que marcam o pertencimento e as práticas cotidianas que definem as diferentes comunidades, as identidades culturais, como forma de apontar as mediações que dotam as práticas de sentido. Por mais que exista uma grande comunidade global, aquela que é marcada pela cultura internacional popular, é apenas por meio da tradução localizada dessa cultura que se efetiva a troca comunicativa, esta pensada sempre como a negociação de sentidos. A manipulação local da imagem global, com todas as negociações, disputas e discussões que certamente sustentaram esse processo, é uma importante pista para que a análise do processo comunicacional se volte cada vez mais ao estudo das mediações que operam na sua significação e nem tanto ao lugar das estruturas e lógicas econômicas que solidifica esse processo, ainda que a contemporaneidade seja efetivamente evidenciada pela hegemonia e triunfo capitalista.

\section{Bibliografia do Artigo}

BAUDRILARD, Jean. Simulacros e Simulações. Ed. Relógio D’Agua, Lisboa, Portugal, 1991.

BEAUD, Paul. Medias, mediations et mediateurs dans la societé industreielle. These, Grenoble, França, 1985.

CANCLINI, N. G Consumidores e Cidadãos. Ed. UFRJ, Rio de Janeiro, Brasil, 1995.

FLUSSER, Vilém. Filosofia da Caixa Preta - Ensaios para um futura filosofia da fotografia. Ed. Relume Dumará, Rio de Janeiro, Brasil, 2002.

GIOIELLI, Rafael L. P. Pistas para entender a identidade no contexto da Globalização. Trabalho apresentado no IV Encontro dos Núcleos de Pesquisa XXVII Congresso Brasileiro de Ciências da Comunicação, Intercom, Porto Alegre, PUC-RS, Brasil, 2004. 
HALL, S. A identidade cultural na pós-modernidade. DP\&A Editora, Rio de Janeiro, Brasil, 2003A.

Quem precisa da identidade? In: Silva, Tomaz Tadeu da. Identidade e diferença. Ed. Vozes, Petrópolis, 2003B. IANNI, O. A Era do Globalismo. Ed. Civilização Brasileira, Rio de Janeiro, Brasil, 2001.

HORCKHEIMER e ADORNO. In: Temas básicos de sociologia. Ed.Cultrix, São Paulo, Brasil, 1973.

IANNI, O. A Sociedade Global. Ed. Civilização Brasileira, Rio de Janeiro, 2003

LEITE, Marcelo Henrique. Fotografia: comunicação e cultura. Trabalho apresentado no IV Encontro dos Núcleos de Pesquisa - XXVII Congresso Brasileiro de Ciências da Comunicação, Intercom, Porto Alegre, PUC-RS, Brasil.2004.

MARTÍN-BARBERO, J. Dos Meios às Mediações. Rio de Janeiro, Ed. UFRJ, 1997. CANCLINI, N. G. Consumidores e cidadãos. Ed. UFRJ, Rio de Janeiro, 1999.

Colombia, 1995/B

Pré-textos. Cen. Editorial, Univ.Del Valle, Cali,

Descentramiento cultural y palimpsestos de

identidad. Rev. Estudos sobre las culturas contemporaneas, Epoca II, Vol.III, n.5, Mexico.

La ciudad virtual. Rev.Univ.del Valle, Cali, Colombia,

1996.

. América Latina e os anos recentes: o estudo da

recepção em comunicação social. In: Sousa, M. W. (org). Sujeito o lado oculto do receptor, Ed.Brasiliense, São Paulo, Brasil, 1995/A.

MIEGE, Bernard. Léspace public: perpetue, elargi et fragmenté. In: Pailliart, Isabelle: L'éspace public et lémprise de Ia communication, ELLUG, Grenoble, França, 1995.

MONTEIRO Paula. Cultura e democracia no processo de globalização. Novos Estudos Cebrap, n.44, São Paulo, Brasil, 1996

ORTIZ, R. Mundialização e cultura. Ed. Brasiliense, São Paulo, 2003.

PIERUCCI, Antonio Flávio. Ciladas da diferença. Ed.34, São Paulo, Brasil, 1999.

SILVA, Tomaz Tadeu da (org). Identidade e diferença. Ed. Vozes, Petrópolis, 2003.

SILVERSTONE, R. New media and community. Paper. London,1999.

SOUSA, Mauro Wilton. Práticas de recepção mediática como práticas de pertencimento público. Revista Novos Olhares, ECA.USP, n.3, 1999. 